\title{
Numerical Study of Entropy Generation due to Coupled Laminar and Turbulent Mixed Convection and Thermal Radiation in an Enclosure Filled with a Semitransparent Medium
}

\author{
M. Goodarzi, ${ }^{1}$ M. R. Safaei, ${ }^{2}$ Hakan F. Oztop, ${ }^{3}$ A. Karimipour, ${ }^{4}$ E. Sadeghinezhad, ${ }^{1}$ \\ M. Dahari, ${ }^{2}$ S. N. Kazi, ${ }^{2}$ and N. Jomhari ${ }^{1}$ \\ ${ }^{1}$ Department of Software Engineering, Faculty of Computer Science \& Information Technology, University of Malaya, \\ 50603 Kuala Lumpur, Malaysia \\ ${ }^{2}$ Department of Mechanical Engineering, Faculty of Engineering, University of Malaya, 50603 Kuala Lumpur, Malaysia \\ ${ }^{3}$ Department of Mechanical Engineering, Technology Faculty, Firat University, Elazig, Turkey \\ ${ }^{4}$ Department of Mechanical Engineering, Najafabad Branch, Islamic Azad University, Isfahan, Iran
}

Correspondence should be addressed to M. R. Safaei; cfd_safaei@yahoo.com

Received 15 October 2013; Accepted 10 December 2013; Published 20 March 2014

Academic Editors: Y. Hara and Y. Zhang

Copyright (C) 2014 M. Goodarzi et al. This is an open access article distributed under the Creative Commons Attribution License, which permits unrestricted use, distribution, and reproduction in any medium, provided the original work is properly cited.

\begin{abstract}
The effect of radiation on laminar and turbulent mixed convection heat transfer of a semitransparent medium in a square enclosure was studied numerically using the Finite Volume Method. A structured mesh and the SIMPLE algorithm were utilized to model the governing equations. Turbulence and radiation were modeled with the RNG $k-\varepsilon$ model and Discrete Ordinates (DO) model, respectively. For Richardson numbers ranging from 0.1 to 10 , simulations were performed for Rayleigh numbers in laminar flow $\left(10^{4}\right)$ and turbulent flow $\left(10^{8}\right)$. The model predictions were validated against previous numerical studies and good agreement was observed. The simulated results indicate that for laminar and turbulent motion states, computing the radiation heat transfer significantly enhanced the Nusselt number $(\mathrm{Nu})$ as well as the heat transfer coefficient. Higher Richardson numbers did not noticeably affect the average Nusselt number and corresponding heat transfer rate. Besides, as expected, the heat transfer rate for the turbulent flow regime surpassed that in the laminar regime. The simulations additionally demonstrated that for a constant Richardson number, computing the radiation heat transfer majorly affected the heat transfer structure in the enclosure; however, its impact on the fluid flow structure was negligible.
\end{abstract}

\section{Introduction}

The heat transfer phenomenon in which natural and forced convections occur simultaneously is known as mixed convection heat transfer. The mixed convection heat transfer is a fundamentally important heat transfer mechanism that takes place in many industrial and technological processes such as designing solar collectors, double-layer glass, buildings for thermal comfort, and cooling electronic parts.

Nonetheless, in applications related to large enclosures, the Rayleigh number is often very big, meaning that the nature of convection in the enclosure is completely turbulent.
Owing to this state, the analysis of turbulent flows inside enclosures is still a challenging subject in fluid mechanics. The reason is that in experimental studies, measuring low speeds in the boundary layers of enclosures with the available probes or sensors is a difficult and daunting task. From a numerical perspective, although new methods including DES, LES, and DNS have achieved significant progress, it is still nearly impossible to completely analyze the stratification in the core of an enclosure. Nonlinearity and coupling of the governing equations make the calculations complicated and time consuming [1]. The complexity of calculating mixed convection has prompted researchers to study natural 
convection. Reference can be made to works accomplished by Braga and de Lemos [2], Kuznetsov and Sheremet [3], and Sheremet [4] among others.

In several instances, however, radiation heat transfer coexists with and has significant impact on the fluid structure. Due to its complexity though, its effect has unfortunately been overlooked in many research works [5-8].

The literature review demonstrates that no extensive studies have been done on the interaction between turbulent mixed convection heat transfer and radiation inside enclosures. Only a limited number of studies consider the effect of radiation on natural convection. As such, these researchers generally focus on air or other neutral gases as radiatively nonparticipating mediums owing to the simplicity of modeling radiation as well as the possibility to solve the governing equations and compute the average Nusselt number $(\mathrm{N} \overline{\mathrm{u}})$ of radiation and convection separately [9-11]. For semitransparent media like water, the convection and radiation governing equations are coupled with each other and therefore should be solved together. In this state, the total Nusselt number $\left(\mathrm{Nu}_{\text {total }}\right)$ cannot be obtained by normally mathematically adding the radiative and convective Nusselt numbers.

The presented literature review indicates that the study of radiation as an effective thermal source is in its early stages. In particular, the effect that radiation has on convection heat transfer in the turbulent flow regime in semitransparent media is not entirely understood. The current study thus investigates the laminar and turbulent mixed convection heat transfer of water in a square enclosure in the presence of thermal radiation. The RNG $k-\varepsilon$ turbulence model $[12,13]$ was applied for turbulent flow analysis. Model validation was accomplished by comparing the simulation results for laminar and turbulent flow regimes with the results found in the literature. The numerical results for streamlines, temperature, entropy and heat transfer in terms of average Nusselt number are presented.

\section{The Governing Equations of Laminar and Turbulent Mixed Convection in Combination with Radiation}

Continuity equation:

$$
\frac{\partial u}{\partial x}+\frac{\partial v}{\partial y}=0
$$

$X$ and $Y$ Momentum Equations:

$$
\begin{aligned}
\frac{\partial u}{\partial t} & +u \frac{\partial u}{\partial x}+v \frac{\partial u}{\partial y} \\
& =-\frac{1}{\rho} \frac{\partial p}{\partial x}+\frac{\partial}{\partial x}\left(v+v_{t}\right)\left(2 \frac{\partial u}{\partial x}\right)+\frac{\partial}{\partial y}\left(v+v_{t}\right)\left(\frac{\partial u}{\partial y}+\frac{\partial v}{\partial x}\right)
\end{aligned}
$$

$$
\begin{aligned}
\frac{\partial v}{\partial t}+ & u \frac{\partial v}{\partial x}+v \frac{\partial v}{\partial y} \\
= & -\frac{1}{\rho} \frac{\partial p}{\partial y}+g \beta\left(T-T_{m}\right)+\frac{\partial}{\partial y}\left(v+v_{t}\right)\left(2 \frac{\partial v}{\partial y}\right) \\
& +\frac{\partial}{\partial x}\left(v+v_{t}\right)\left(\frac{\partial v}{\partial x}+\frac{\partial u}{\partial y}\right) .
\end{aligned}
$$

Energy equation:

$$
\begin{aligned}
\frac{\partial T}{\partial t} & +u \frac{\partial T}{\partial x}+v \frac{\partial T}{\partial y} \\
& =\frac{\partial}{\partial x}\left(\frac{v}{\operatorname{Pr}}+\frac{v_{t}}{\sigma_{T}}\right) \frac{\partial T}{\partial x}+\frac{\partial}{\partial y}\left(\frac{v}{\operatorname{Pr}}+\frac{v_{t}}{\sigma_{T}}\right) \frac{\partial T}{\partial y}
\end{aligned}
$$

Turbulent Kinetic Energy Transport $(K)$ equation:

$$
\begin{aligned}
\frac{\partial k}{\partial t} & +u \frac{\partial k}{\partial x}+v \frac{\partial k}{\partial y} \\
& =\frac{\partial}{\partial x}\left(v+\frac{v_{t}}{\sigma_{k}}\right) \frac{\partial k}{\partial x}+\frac{\partial}{\partial y}\left(v+\frac{v_{t}}{\sigma_{k}}\right) \frac{\partial k}{\partial y}+P_{k}+G_{k}-\varepsilon
\end{aligned}
$$

Dissipation of Turbulent Kinetic Energy Transport $(\varepsilon)$ equation:

$$
\begin{aligned}
\frac{\partial \varepsilon}{\partial t}+ & u \frac{\partial \varepsilon}{\partial x}+v \frac{\partial \varepsilon}{\partial y} \\
= & \frac{\partial}{\partial x}\left(v+\frac{v_{t}}{\sigma_{\varepsilon}}\right) \frac{\partial \varepsilon}{\partial x}+\frac{\partial}{\partial y}\left(v+\frac{v_{t}}{\sigma_{\varepsilon}}\right) \frac{\partial \varepsilon}{\partial y}+C_{1} \frac{\varepsilon}{k} P_{k} \\
& +C_{2} \frac{\varepsilon^{2}}{k}+C_{3} \frac{\varepsilon}{k} G_{k}-R_{\varepsilon} .
\end{aligned}
$$

The Eddy Viscosity from the Prandtl-Kolmogorov Relation is obtained by

$$
v_{t}=C_{\mu} f_{\mu} \frac{k^{2}}{\varepsilon}
$$

The Stress Production term, $P_{k}$, can also be obtained by

$$
P_{k}=v_{t}\left[2\left(\frac{\partial u}{\partial x}\right)^{2}+2\left(\frac{\partial v}{\partial x}\right)^{2}+\left(\frac{\partial u}{\partial y}+\frac{\partial v}{\partial y}\right)^{2}\right]
$$

The Buoyancy Term, $G_{k}$, can be expressed as follows:

$$
G_{k}=-g \beta \frac{v_{t}}{\sigma_{t}} \frac{\partial T}{\partial y} \text {. }
$$

For term $R_{\varepsilon}$ in equation $\varepsilon$ we have

$$
\begin{gathered}
R_{\varepsilon}=\frac{C_{\mu} \rho \eta^{3}\left(1-\left(\eta / \eta_{0}\right)\right)}{1+\beta \eta^{3}} \frac{\varepsilon^{2}}{k}, \\
\eta=\frac{S k}{\varepsilon}
\end{gathered}
$$




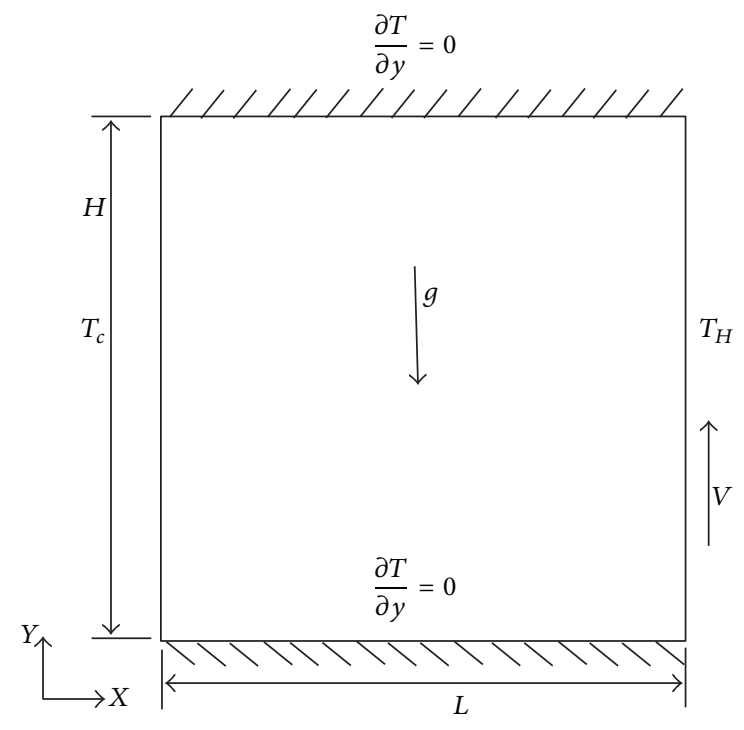

Figure 1: Schematic of analyzed configuration.

where the turbulence model coefficients are as follows:

$$
\begin{gathered}
C_{\mu}=0.0845, \quad \sigma_{k}=1, \quad \sigma_{\varepsilon}=1.3, \\
C_{1}=1.42, \quad C_{2}=1.68, \quad \eta_{0}=4.38, \\
\beta=0.012, \quad K=0.41 .
\end{gathered}
$$

The Discrete Ordinates (DO) radiation model for spectral intensity is $[12,15]$ :

$$
\begin{aligned}
\nabla & \cdot\left(I_{\lambda}(\vec{r}, \vec{s}) \vec{s}\right)+\left(a_{\lambda}+\sigma_{s}\right) I_{\lambda}(\vec{r}, \vec{s}) \\
& =a_{\lambda} n^{2} I_{b \lambda}+\frac{\sigma_{s}}{4 \pi} \int_{0}^{4 \pi} I_{\lambda}\left(\vec{r}, \vec{s}^{\prime}\right) \phi\left(\vec{s}, \vec{s}^{\prime}\right) d \Omega^{\prime}
\end{aligned}
$$

where $\lambda$ is the wavelength, $a_{\lambda}$ is the spectral absorption coefficient, and $I_{b \lambda}$ is the black body intensity provided by the Planck function.

The total intensity $(I(\vec{r}, \vec{s}))$ in direction $\vec{s}$ and at position $\vec{r}$ is calculated by

$$
I(\vec{r}, \vec{s})=\sum_{k} I_{\lambda_{k}}(\vec{r}, \vec{s}) \Delta \lambda_{k}
$$

where the summation is over the wavelength bands.

Entropy Generation [16]:

$$
\begin{aligned}
S_{\text {gen }}= & \frac{k}{T^{2}}\left[\left(\frac{\partial T}{\partial x}\right)^{2}+\left(\frac{\partial T}{\partial y}\right)^{2}\right] \\
& +\frac{\mu}{T}\left\{2\left[\left(\frac{\partial v}{\partial x}\right)^{2}+\left(\frac{\partial v}{\partial y}\right)^{2}\right]+\left(\frac{\partial v}{\partial y}+\frac{\partial v}{\partial x}\right)^{2}\right\} .
\end{aligned}
$$

\section{Boundary Conditions}

Figure 1 illustrates a schematic of the configuration analyzed in the present study along with the boundary conditions.
The specific boundary conditions for the present study are:

$$
\begin{gathered}
T=T_{c}, \quad u=v=0, \quad 0<y<1, \quad x=0, \\
T=T_{h}, \quad v=v_{\text {lid }}, \quad u=0, \quad 0<y<1, \quad x=1, \\
\frac{\partial T}{\partial y}=0, \quad u=v=0, \quad 0<x<1, \quad y=0, \\
\frac{\partial T}{\partial y}=0, \quad u=v=0, \quad 0<x<1, \quad y=1 .
\end{gathered}
$$

3.1. Wall Function Modeling. The standard wall function described by Launder and Spalding [17] and used in Abedini et al. [18] and Goodarzi et al. [19] is a semiempirical formula based on the established properties of turbulence in the inertial sub-layer near a wall. In this approach, the velocity at the first grid is given as follows:

$$
U^{+}=2.389 \ln \left(9.793 Y^{+}\right),
$$

where

$$
\begin{gathered}
U^{+}=\frac{U_{P} C_{\mu}^{0.25} K_{P}^{0.5}}{\tau_{w} / \rho}, \\
y^{+}=\frac{\rho Y_{P} C_{\mu}^{0.25} K_{P}^{0.5}}{\mu} .
\end{gathered}
$$

The logarithmic law for the mean velocity is valid for the range $11 \leq y^{+} \leq 300$. When the meshes are in such a way that $y^{+} \leq 11$ at the wall-adjacent cells, in the viscous sublayer, the linear velocity profile holds. That is,

$$
U^{+}=Y^{+} \text {. }
$$

For the temperature boundary conditions:

$$
\begin{aligned}
T^{+} & =\frac{\rho C_{P}\left(T_{W}-T_{P}\right) C_{\mu}^{0.25} K_{P}^{0.5}}{\dot{q}} \\
& = \begin{cases}\operatorname{Pr} Y^{+} & \left(Y^{+}<Y_{T}^{+}\right) \\
0.85\left[2.389 \ln \left(9.793 Y^{+}\right)+\zeta\right] & \left(Y^{+}>Y_{T}^{+}\right),\end{cases}
\end{aligned}
$$

where

$$
\zeta=9.24\left[\left(\frac{\operatorname{Pr}}{0.85}\right)^{0.75}-1\right]\left[1+0.28 e^{-0.007 \operatorname{Pr} / 0.85}\right] .
$$

For the turbulence $K-\varepsilon$ model, the boundary conditions for turbulent kinetic energy are given as follows:

$$
\frac{\partial K}{\partial Y}=0 .
$$

The corresponding turbulence kinetic energy production term is given by

$$
P_{k} \approx \tau_{w} \frac{\partial u}{\partial y}=\tau_{w} \frac{\tau_{w}}{0.4187 \rho C_{\mu}^{0.25} Y_{p} K_{P}^{0.5}} .
$$


TABLE 1: (a) Comparison of the average Nusselt number with Sharif [14] work. (b) Comparison of the average Nusselt number with Xamán et al. [10] work.

(a)

\begin{tabular}{|c|c|c|c|c|}
\hline \multicolumn{2}{|c|}{$\mathrm{Ri}$, surface } & $\mathrm{N} \overline{\mathrm{u}}[14]$ & \multicolumn{2}{|c|}{$\mathrm{N} \overline{\mathrm{u}}$ (present study) } \\
\hline \multicolumn{2}{|c|}{ 1, cold wall } & 3.27 & & 3.273 \\
\hline \multicolumn{2}{|c|}{ 1, hot wall } & 3.58 & & 3.588 \\
\hline \multicolumn{5}{|c|}{ (b) } \\
\hline $\mathrm{Ra}$ & $\begin{array}{l}\mathrm{Nu} \text { with } \\
\text { radiation [10] }\end{array}$ & $\begin{array}{l}\mathrm{N} \bar{u} \text { without } \\
\text { radiation [10] }\end{array}$ & $\begin{array}{c}\mathrm{N} \overline{\mathrm{u}} \text { with } \\
\text { radiation } \\
\text { (present study) }\end{array}$ & $\begin{array}{l}\mathrm{Nu} \text { without } \\
\text { radiation } \\
\text { (present study) }\end{array}$ \\
\hline $10^{4}$ & 2.55 & 1.83 & 2.48 & 1.77 \\
\hline $10^{12}$ & 972.51 & 591.27 & 969.96 & 589.02 \\
\hline
\end{tabular}

At the wall-adjacent cells, the $\varepsilon$ equation is not solved. But instead, $\varepsilon_{P}$ is evaluated as [19]:

$$
\varepsilon_{P}=\frac{C_{\mu}^{0.75} K_{p}^{1.5}}{k Y_{p}}
$$

\section{Numerical Method}

In order to solve the governing equations, the FLUENT commercial code based on the finite volume method was used and is described in detail in [20]. The finite volume method is a specific case of the weighting residual method, where the computational field is divided into finite control volumes as each node corresponds to a control volume. The differential equation is subsequently integrated over each finite volume [21, 22].

The Second Order Upwind scheme was engaged to discretize the convective and diffusive terms, while the SIMPLE algorithm [23, 24] was selected for the pressure-velocity coupling. The calculation was considered converged when the residuals for all equations dropped below $10^{-7}$. Such criteria for the equations guarantee highly precise solutions [25].

\section{Numerical Procedure Validation}

5.1. Laminar Mixed Convection Validation. For the purpose of validating the laminar mixed convection flow part of the analysis, the problem described by Sharif [14] was solved and the present simulation results were compared with it. In [14], the laminar mixed convection heat transfer of water in a liddriven cavity with an aspect ratio of 0.1 , cooled from the bottom and heated from the top movable wall, was studied via the finite volume method. Calculations were done for $0.1 \leq \mathrm{Ri} \leq 10$, while the Reynolds number was kept fixed at $\mathrm{Re}=408.21$. The computed average Nusselt number in $\mathrm{Ri}=$ 1 was contrasted with the work of Sharif [14] in Table 1(a). The table illustrates excellent agreement between the present simulation results and those in Sharif [14]. Therefore, the current numerical procedure can be applied with confidence in the simulation of laminar mixed convection flows.
TABLE 2: (a) Grid independency tests for laminar regime $\left(\mathrm{Ra}=10^{4}\right)$ (with radiation). (b) Grid independency tests for turbulence RNG $k$ - $\varepsilon$ model $\left(\mathrm{Ra}=10^{8}\right)$ (with radiation).

(a)

\begin{tabular}{|c|c|c|c|}
\hline Number of grids & $50 \times 50$ & $100 \times 100$ & $200 \times 200$ \\
\hline $\begin{array}{l}\text { Average Nusselt number } \\
\text { for } \mathrm{Ri}=0.1\end{array}$ & 0.771516 & 0.771516 & 0.771512 \\
\hline $\begin{array}{l}\text { Average Nusselt number } \\
\text { for } \mathrm{Ri}=1\end{array}$ & 0.7715094 & 0.7715094 & 0.7715082 \\
\hline $\begin{array}{l}\text { Average Nusselt number } \\
\text { for } \mathrm{Ri}=10\end{array}$ & 0.7715067 & 0.7715067 & 0.7715053 \\
\hline
\end{tabular}

(b)

\begin{tabular}{|c|c|c|c|}
\hline Number of grids $(\mathrm{Ri}=0.1)$ & $200 \times$ & $250 \times 250$ & $300 \times 300$ \\
\hline $\begin{array}{l}\text { verage Nusselt number } \\
\mathrm{r} \mathrm{Ri}=0.1\end{array}$ & 26.0 & 26.0 & 26 \\
\hline Number of grids $(\mathrm{Ri}=1)$ & 0 & 25 & 00 \\
\hline Nusselt number & 26.0 & 26.0 & 26. \\
\hline Number of grids $(\mathrm{Ri}=10)$ & $250 \times 250$ & 300 & $400 \times 400$ \\
\hline $\begin{array}{l}\text { Average Nusse } \\
\text { for } \mathrm{Ri}=10\end{array}$ & 26.045232 & 26.045226 & 26.045223 \\
\hline
\end{tabular}

5.2. Turbulent Convection and Radiation Heat Transfer Validation. The present numerical procedure for solving laminar and turbulent convection conjugating radiation was verified against the existing results of Xamán et al. [10]. In that work, laminar and turbulent natural convection combined with surface radiation and conduction heat transfer in a square cavity filled with air was analyzed numerically by finite volume method. Calculations were done for $10^{3} \leq \mathrm{Ra} \leq$ $10^{12}, \Delta T=14^{\circ} \mathrm{C}$ and surface solar radiation $750 \mathrm{~W} \mathrm{~m}^{-2}$. For $\mathrm{Ra}=10^{4}$ (laminar regime) and $10^{12}$ (turbulent regime), the average Nusselt number is shown in Table 1(b) and compared with the results of Xamán et al. [10]. Table 1(b) demonstrates reasonable concord between the outcomes of the present work and those of Xamán et al. [10]. The small discrepancies seen in this table may be due to having ignored the walls' conduction in the present study.

5.3. Grid Independence. Structured nonuniform grid distributions were applied to discretize the computation domain. The significance of the temperature and velocity gradients near the walls caused the grid to be more refined there. Various grid distribution types were tested to ensure the results were grid independent. The grid independence for each turbulence model and different Ri was tested separately. Tables 2(a) and 2(b) are two examples indicative of several tests carried out in the grid study.

\section{Results and Discussion}

This study was meant to analyze the effect of radiation on flow-induced buoyancy in a square enclosure $(H=L)$. It was assumed that the horizontal walls of the enclosure are adiabatic; the right moving wall is $T_{1}=323 \mathrm{~K}$ and the 
TABLE 3: The effect of radiation on the average Nusselt number $(\mathrm{N} \overline{\mathrm{u}})$.

\begin{tabular}{lcccccc}
\hline \multirow{2}{*}{$\mathrm{Ra}$} & \multicolumn{3}{c}{$\mathrm{N} \overline{\mathrm{u}}$ with radiation } & \multicolumn{3}{c}{ Ne without radiation } \\
& $\mathrm{Ri}=0.1$ & $\mathrm{Ri}=1$ & $\mathrm{Ri}=10$ & $\mathrm{Ri}=0.1$ & $\mathrm{Ri}=1$ & 0.642925 \\
\hline $10^{4}$ (Laminar Regime) & 0.771514 & 0.771509 & 0.771506 & 0.642928 & 0.642922 \\
$10^{8}$ (Turbulent Regime) & 26.087826 & 26.083974 & 26.045226 & 19.295729 & 19.292880 & 19.292760 \\
\hline
\end{tabular}

TABLE 4: The effect of radiation on the maximum value of stream function.

\begin{tabular}{|c|c|c|c|c|c|c|}
\hline \multirow{2}{*}{$\mathrm{Ra}$} & \multicolumn{3}{|c|}{$\Psi$ with radiation } & \multicolumn{3}{|c|}{$\Psi$ without radiation } \\
\hline & $\mathrm{Ri}=0.1$ & $\mathrm{Ri}=1$ & $\mathrm{Ri}=10$ & $\mathrm{Ri}=0.1$ & $\mathrm{Ri}=1$ & $\mathrm{Ri}=10$ \\
\hline $10^{4}$ & 0.0007711 & 0.0007710 & 0.0007710 & 0.0007682 & 0.0007678 & 0.0007672 \\
\hline $10^{8}$ & 0.0007709 & 0.0007708 & 0.0007708 & 0.0007679 & 0.0007673 & 0.0007668 \\
\hline
\end{tabular}

left wall is $T_{2}=283 \mathrm{~K}$ with $1000 \mathrm{~W} / \mathrm{m}^{2}$ irradiation in both walls. The enclosure walls are made of iron and are supposed to be opaque. Fluid density was computed by applying the Boussinesq approximation $[9,10]$. The other thermophysical and optical properties of the fluid were assumed to be constants. In order to achieve a higher $\mathrm{Ra}$, the dimensions of the enclosure were augmented.

Table 3 describes the average Nusselt number $(N \bar{u})$ values inside the enclosure for different Richardson numbers in the laminar and turbulent states of motion. The table clearly shows that for laminar and turbulent regimes, the average Nusselt number and therefore heat transfer rate inside the enclosure increased by over $20 \%$ and $35 \%$, respectively when computing the radiation heat transfer in the calculation. It is also clear from this table that due to the great influence that radiation has on the nature of flow, the average Nusselt number remained nearly fixed for various Richardson numbers. In the other words, the effect of natural, mixed, or forced convection heat transfer inside the enclosure can totally disappear when the effect of radiation is considered in the calculation. Furthermore, the extra mixing in the turbulent flow regime leads to a higher heat transfer rate than in the laminar regime.

Table 4 illustrates the effect of radiation on the maximum values of stream function. At a quick glance, the effect of thermal radiation on fluid structure is obviously not remarkable. There is only less than $1 \%$ difference between the maximum values of stream functions in the presence of thermal radiation, meaning that the effect of radiation on the structure of fluid flow can be ignored due to the high cost of radiation computing.

For the laminar and turbulent flow regimes, Figures 2 and 3 illustrate the temperature diagrams at $X / L=0.5$ inside the enclosure for different Richardson numbers. For both cases, the temperature diagram has a linear trend inside the height of the enclosure but for $0 \leq Y / H \leq 0.2$ and $0.8 \leq Y / H \leq$ 1 , one concavity and one convexity reduce the discipline of the temperature diagram. However, as seen in the figures, the influence of radiation on temperature is outstanding. In this state, the temperature difference range is more compact than with pure convection. The difference is $1.5 \mathrm{~K}$ near the upper wall and $1.3 \mathrm{~K}$ near the lower wall.

Figures 4 and 5 show the average of entropy diagrams for the laminar and turbulent regimes. It is evident that

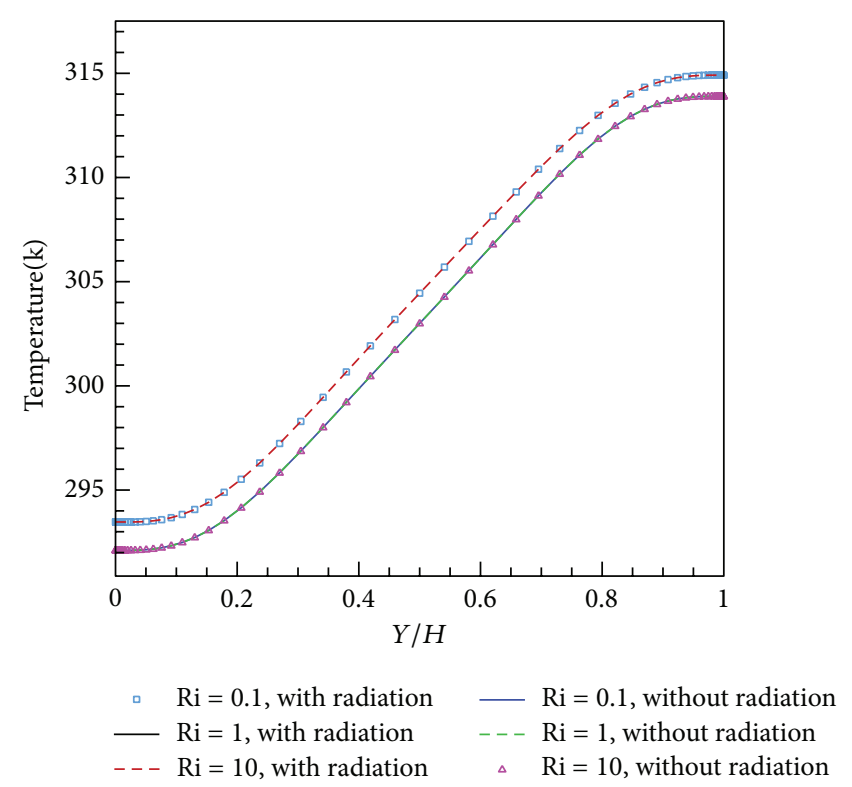

FIGURE 2: Temperature representation in mid-length for different Richardson numbers in laminar flow regime.

the values of entropy vaguely increase (roughly $4.3 \mathrm{~J} \mathrm{~K}^{-1}$ ) by computing radiation in the calculation. However, with linear regression, the correlations between the Richardson numbers and entropy are obtained as follows:

$S_{\max }=-7 \times 10^{-5} \mathrm{Ri}+284.02$

For Laminar Flow and the presence of radiation,

$S_{\max }=-6 \times 10^{-5} \mathrm{Ri}+279.76$

For Laminar Flow and without radiation,

$S_{\max }=-9 \times 10^{-6} \mathrm{Ri}+284.02$

For Turbulent Flow and the presence of radiation,

$S_{\max }=-8 \times 10^{-6} \mathrm{Ri}+279.76$

For Turbulent Flow and without radiation. 


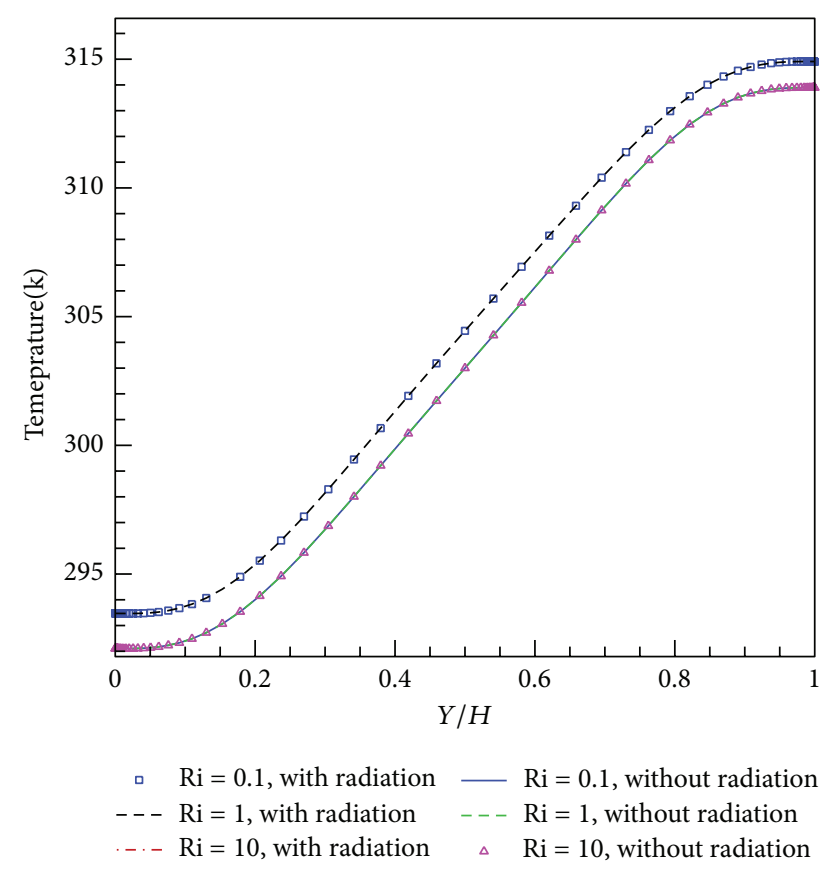

FIGURE 3: Temperature representation in mid-length for different Richardson numbers in turbulent flow regime.

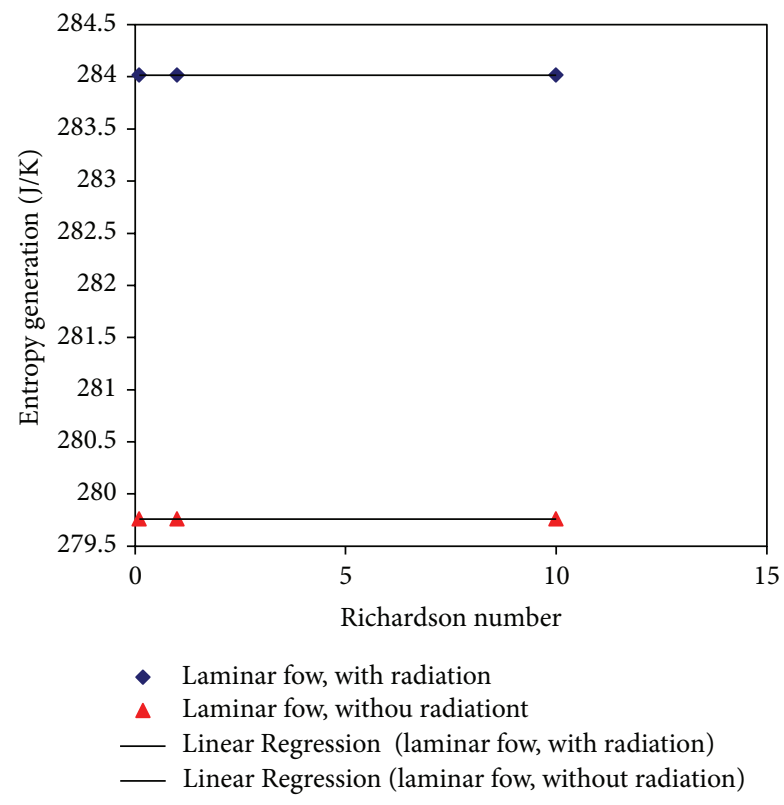

FIGURE 4: Average of entropy representation for different Richardson numbers in laminar flow regime.

\section{Conclusion}

The present study investigated the combination of radiation with mixed convection heat transfer and fluid flow inside a square enclosure with a right hot moving wall. The main dimensionless parameter here was the Richardson number which varied from 0.1 to 10 . The Rayleigh numbers were fixed at $10^{4}$ for laminar flow and $10^{8}$ for turbulent flow. The flow and

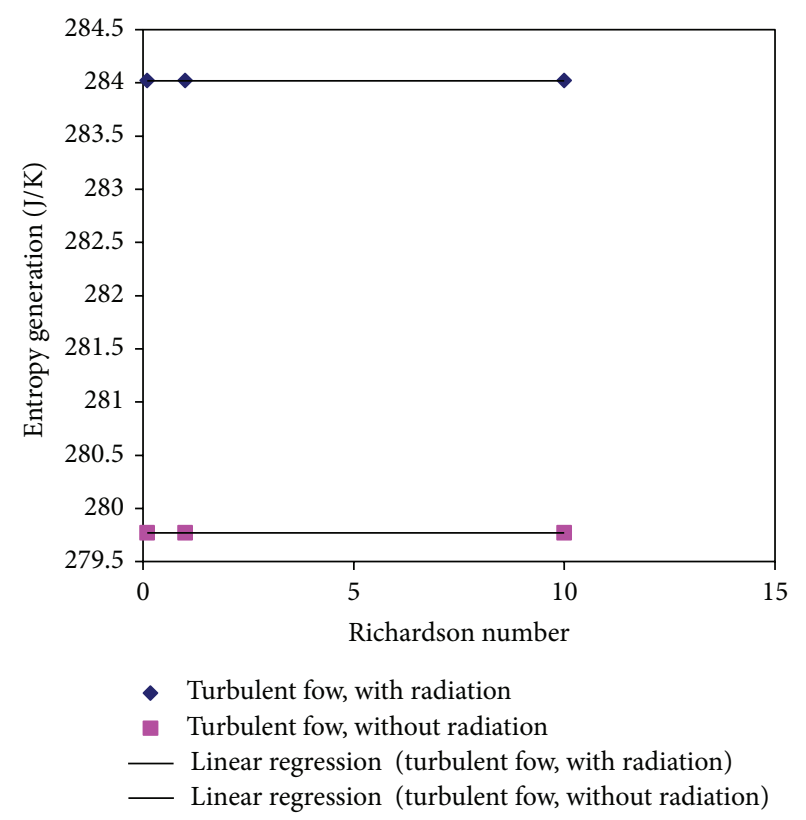

FIgURE 5: Average of entropy representation for different Richardson numbers in turbulent flow regime.

temperature fields as well as various parameters like entropy and average Nusselt number were evaluated.

The study has led to the following conclusions:

(i) For both laminar and turbulent regimes, the heat transfer rate is enhanced by computing the effect of radiation.

(ii) Due to additional mixing in the turbulent flow regime, the heat transfer rate is generally higher than in the laminar regime.

(iii) For both laminar and turbulent regimes, in the presence of radiation heat transfer, the average Nusselt number is almost fixed for different Richardson numbers.

(iv) At low and moderate temperature differences, the effect of radiation heat transfer on the structure of fluid flow is insignificant.

\section{Nomenclature}

$P$ : $\quad$ Pressure $\left(\mathrm{N} \mathrm{m}^{-2}\right)$

$T: \quad$ Temperature $(\mathrm{K})$

$K$ : Turbulence kinetic energy $\left(\mathrm{m}^{2} \mathrm{~s}^{-2}\right)$

S: $\quad$ Entropy $\left(\mathrm{JK}^{-1}\right)$

$t$ : Time (s)

$u, v$ : Velocities components in $X$ and $Y$ directions $\left(\mathrm{m} \mathrm{s}^{-1}\right)$ 


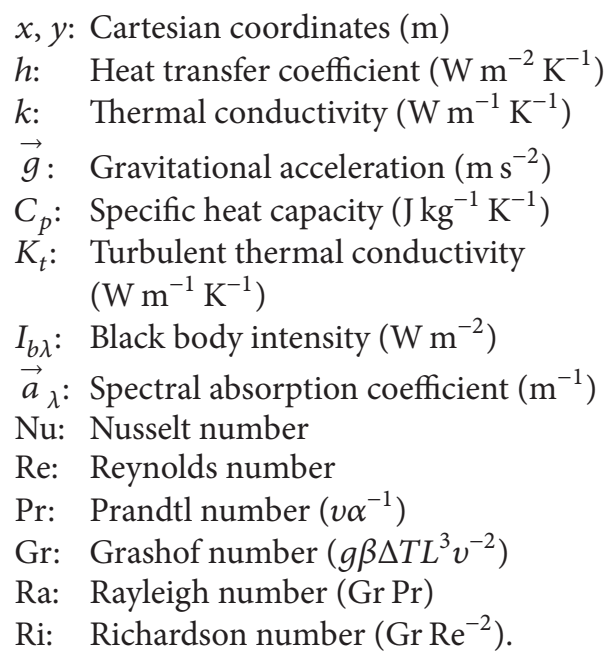

\section{Greek Symbols}

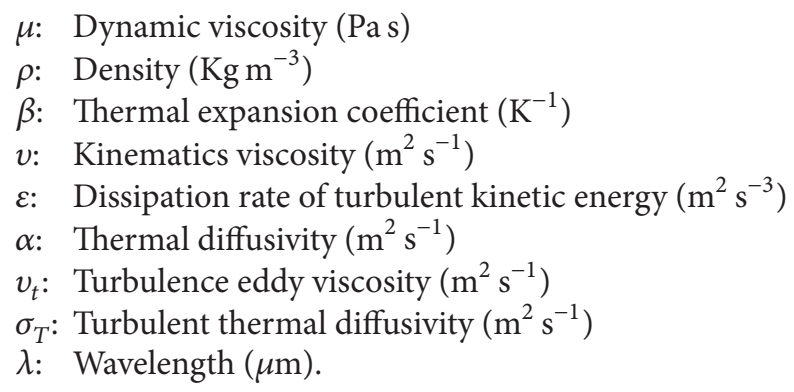

\section{Subscripts}

0: Inlet conditions.

\section{Conflict of Interests}

The authors declare that there is no conflict of interests regarding the publication of this paper.

\section{Acknowledgments}

The authors gratefully acknowledge High Impact Research Grant UM.C/HIR/MOHE/ENG/23, UMRG Grant RP012C13AET and Faculty of Engineering, University of Malaya, Malaysia, for support in conducting this research work.

\section{References}

[1] M. R. Safaei, H. R. Goshayeshi, B. S. Razavi, and M. Goodarzi, "Numerical investigation of laminar and turbulent mixed convection in a shallow water-filled enclosure by various turbulence methods," Scientific Research and Essays, vol. 6, no. 22, pp. 48264838, 2011.

[2] E. J. Braga and M. J. S. de Lemos, "Laminar and turbulent free convection in a composite enclosure," International Journal of Heat and Mass Transfer, vol. 52, no. 3-4, pp. 588-596, 2009.
[3] G. V. Kuznetsov and M. A. Sheremet, "Numerical simulation of turbulent natural convection in a rectangular enclosure having finite thickness walls," International Journal of Heat and Mass Transfer, vol. 53, no. 1-3, pp. 163-177, 2010.

[4] M. A. Sheremet, "Mathematical simulation of conjugate turbulent natural convection in an enclosure with local heat source," Thermophysics and Aeromechanics, vol. 18, no. 1, pp. 107-121, 2011.

[5] A. Marafie, K. Khanafer, B. Al-Azmi, and K. Vafai, "NonDarcian effects on the mixed convection heat transfer in a metallic porous block with a confined slot jet," Numerical Heat Transfer A, vol. 54, no. 7, pp. 665-685, 2008.

[6] H. R. Goshayshi, M. R. Safaei, and Y. Maghmoumi, "Numerical simulation of unsteady turbulent and laminar mixed convection in rectangular enclosure with hot upper moving wall by finite volume method," in Proceedings of the 6th International Chemical Engineering Congress and Exhibition (ICheC'09), Kish Island, Iran, 2009.

[7] M. R. Safaei, Y. Maghmoumi, and A. Karimipour, "Numerical investigation of turbulence mixed convection heat transfer of water and drilling mud inside a square enclosure by finite volume method," in Proceedings of the International Meeting on Advances in Thermofluids (IMAT'11), Melaka, Malaysia, October 2011.

[8] A. Karimipour, M. Afrand, M. Akbari, and M. R. Safaei, "Simulation of fluid flow and heat transfer in the inclined enclosure," International Journal of Mechanical and Aerospace Engineering, vol. 6, pp. 86-91, 2012.

[9] A. K. Sharma, K. Velusamy, and C. Balaji, "Interaction of turbulent natural convection and surface thermal radiation in inclined square enclosures," Heat and Mass Transfer, vol. 44, no. 10, pp. 1153-1170, 2008

[10] J. Xamán, J. Arce, G. Álvarez, and Y. Chávez, "Laminar and turbulent natural convection combined with surface thermal radiation in a square cavity with a glass wall," International Journal of Thermal Sciences, vol. 47, no. 12, pp. 1630-1638, 2008.

[11] A. K. A. Shati, S. G. Blakey, and S. B. M. Beck, "An empirical solution to turbulent natural convection and radiation heat transfer in square and rectangular enclosures," Applied Thermal Engineering, vol. 51, pp. 364-370, 2013.

[12] H. Zeinivand and F. Bazdidi-Tehrani, "Investigation of radiative heat transfer and three thermal radiation models in a turbulent non-premixed methane/air flame," Heat Transfer Research, vol. 42, no. 6, pp. 571-593, 2011.

[13] M. R. Safaei and H. R. Goshayshi, "Numerical simulation of laminar and turbulence flow of air: natural\& mechanical ventilation inside a room," in Proceedings of the 10th REHVA World Congress, Clima 2010: Sustainable Energy Use in Buildings, Antalya, Turkey, 2010.

[14] M. A. R. Sharif, "Laminar mixed convection in shallow inclined driven cavities with hot moving lid on top and cooled from bottom," Applied Thermal Engineering, vol. 27, no. 5-6, pp. 10361042,2007

[15] K. Y. Litvintsev and A. A. Dekterev, "Comparison of the finitevolume and discrete-ordinate methods and diffusion approximation for the radiative heat transfer equation," Heat Transfer Research, vol. 39, no. 8, pp. 653-660, 2008.

[16] O. Mahian, A. Kianifar, C. Kleinstreuer et al., "A review of entropy generation in nanofluid flow," International Journal of Heat and Mass Transfer, vol. 65, pp. 514-532, 2013. 
[17] B. E. Launder and D. B. Spalding, "The numerical computation of turbulent flows," Computer Methods in Applied Mechanics and Engineering, vol. 3, no. 2, pp. 269-289, 1974.

[18] E. Abedini, A. Behzadmehr, S. M. H. Sarvari, and S. H. Mansouri, "Numerical investigation of subcooled flow boiling of a nanofluid," International Journal of Thermal Sciences, vol. 64, pp. 232-239, 2013.

[19] M. Goodarzi, M. R. Safaei, K. Vafai et al., "Investigation of nanofluid mixed convection in a shallow cavity using a two-phase mixture model," International Journal of Thermal Sciences, vol. 75, pp. 204-220, 2014.

[20] S. V. Patankar, Numerical Heat Transfer and Fluid Flow, Hemisphere, Washington, DC, USA, 1980.

[21] M. R. Safaei, B. Rahmanian, and M. Goodarzi, "Numerical study of laminar mixed convection heat transfer of power-law non-Newtonian fluids in square enclosures by finite volume method," International Journal of Physical Sciences, vol. 6, no. 33, pp. 7456-7470, 2011.

[22] M. R. Safaei, M. Goodarzi, and M. Mohammadi, "Numerical modeling of turbulence mixed convection heat transfer in air filled enclosures by finite volume method," International Journal of Multiphysics, vol. 5, no. 4, pp. 307-323, 2011.

[23] A. Karimipour, M. H. Esfe, M. R. Safaei, D. T. Semiromi, and S. N. Kazi, "Mixed convection of Copper-Water nanofluid in a shallow inclined lid driven cavity using lattice Boltzmann method," Physica A, vol. 402, pp. 150-168, 2014.

[24] M. Goodarzi, M. R. Safaei, A. Karimipour et al., "Comparison of the finite volume and lattice Boltzmann methods for solving natural convection heat transfer problems inside cavities and enclosures," Abstract and Applied Analysis, vol. 2014, Article ID 762184, 15 pages, 2014.

[25] M. R. Safaei and H. R. Goshayshi, "Investigation of turbulence mixed convection in air filled enclosures," Journal of Chemical Engineering and Materials Science, vol. 2, no. 6, pp. 87-95, 2011. 

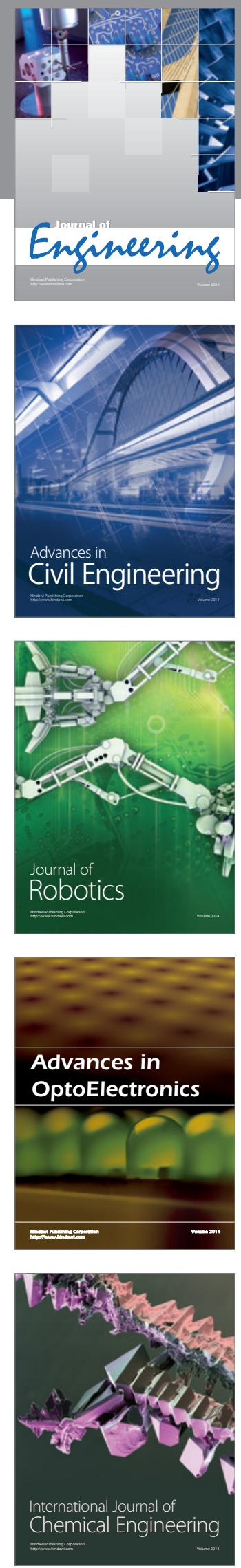

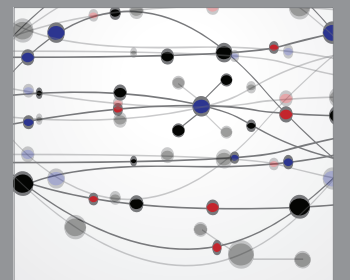

The Scientific World Journal
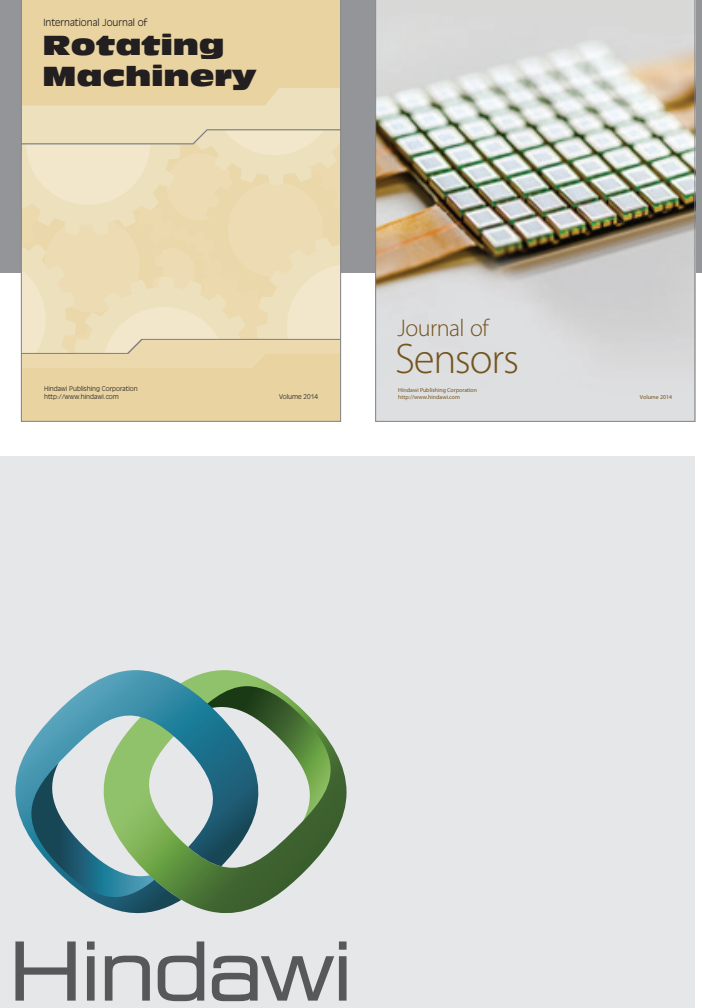

Submit your manuscripts at http://www.hindawi.com
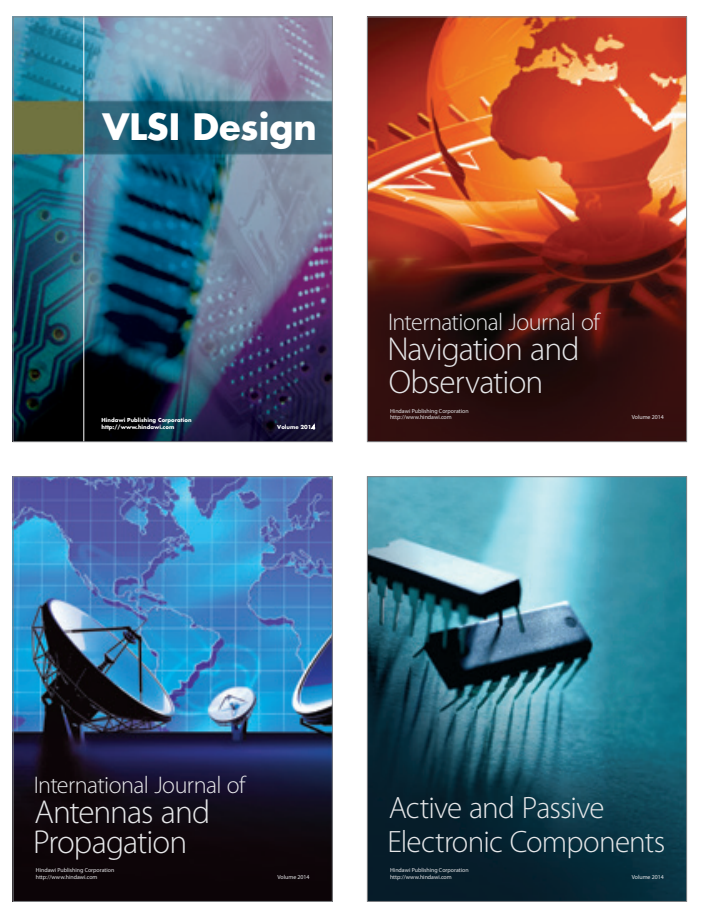
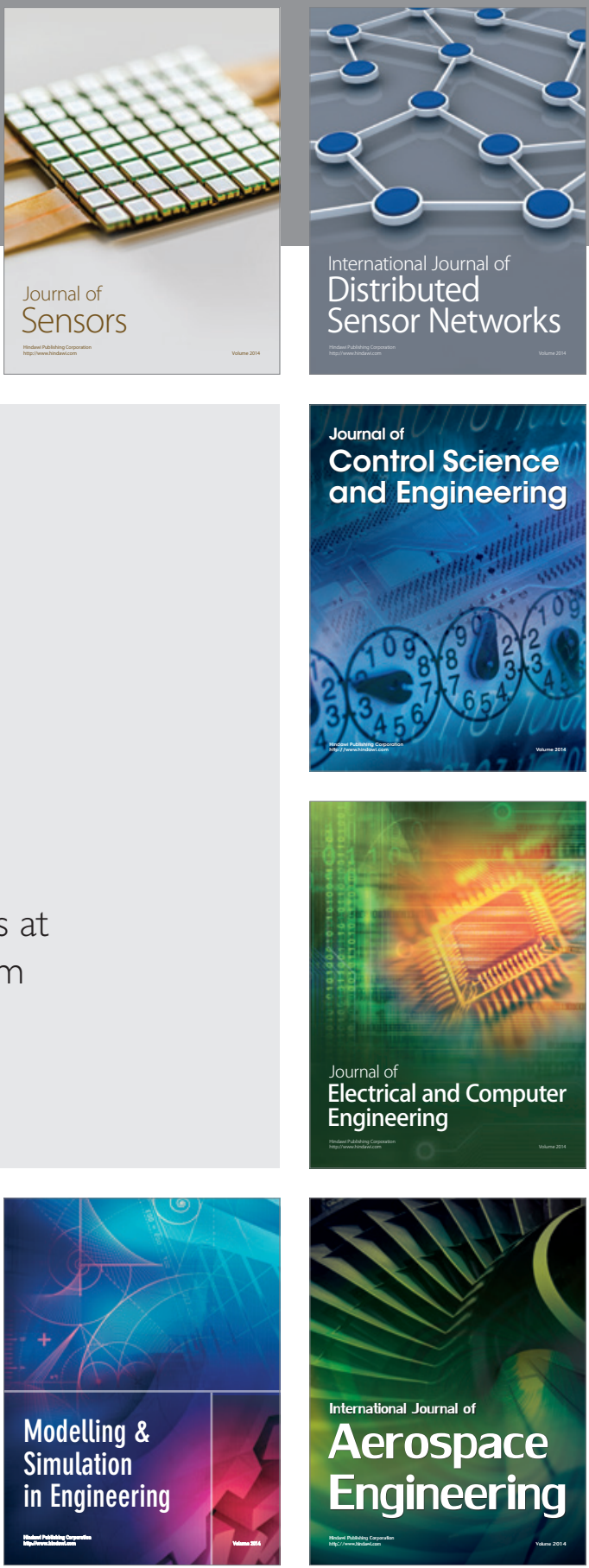

Journal of

Control Science

and Engineering
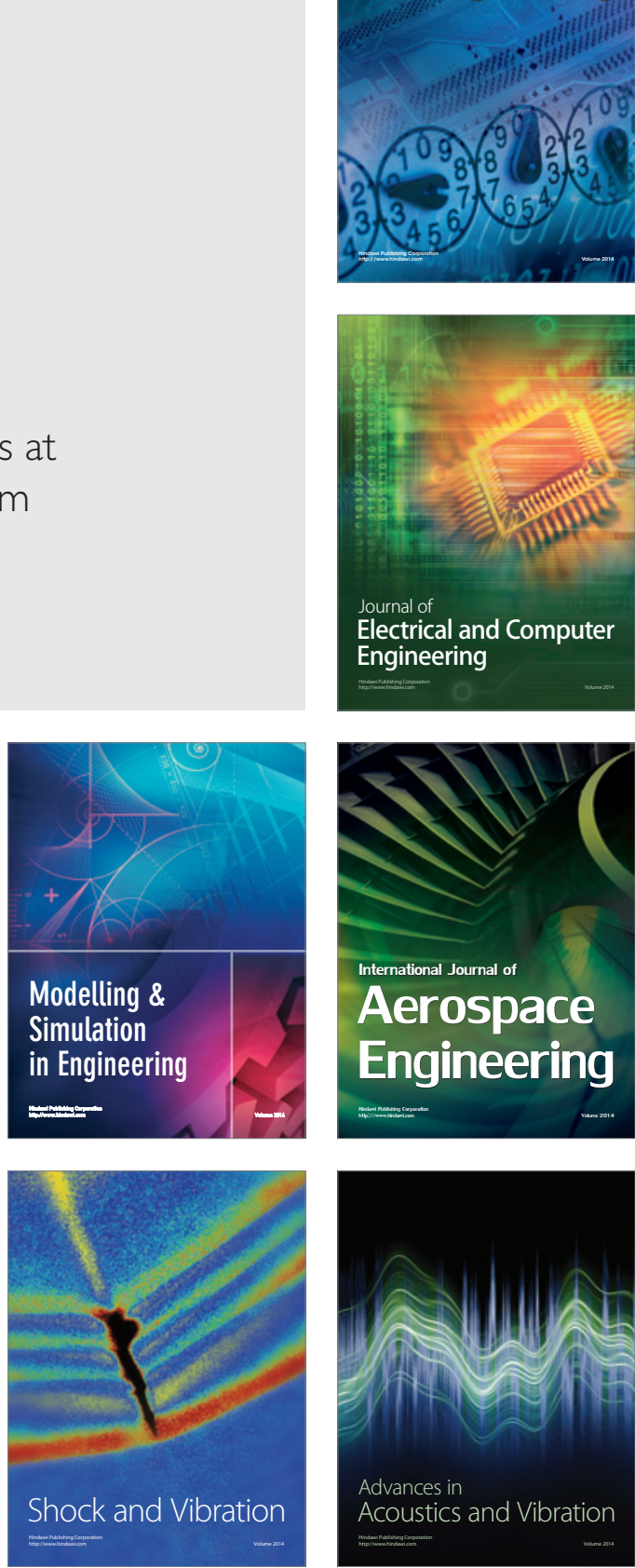